\title{
Cultural Differences in the Use of Instant Messaging in Asia and North America
}

\author{
Shipra Kayan ${ }^{+}$, Susan R. Fussell ${ }^{*}$, Leslie D. Setlock \\ +Oracle Corp \\ 500 Oracle Parkway \\ Redwood Shores, CA 94065 USA \\ +14157347585 \\ shipra.kayan@oracle.com \\ "Carnegie Mellon University \\ 5000 Forbes Avenue \\ Pittsburgh, PA 15213 USA \\ +1 412-268-7125 \\ [sfussell, Isetlo]@cs.cmu.edu
}

\begin{abstract}
Information technologies have the potential to facilitate crosscultural collaboration, but this potential may be limited by different styles of IT use in different cultures. We report the results of a preliminary study and a larger follow-up study that focus on the use of Instant Messaging (IM) in North America and Asia. Consistent with the distinction between Western individualistic, low-context cultures and Eastern collectivistic, high-context cultures, we found that multi-party chat, audio-video chat and emoticons were much more popular in Asia than in North America. We conclude that cultural differences should be taken into consideration when designing tools for cross-cultural communication.
\end{abstract}

\section{Categories and Subject Descriptors}

K.4.3 [Computers and Society]: Organizational Impacts: computer-supported cooperative work

\section{General Terms}

Design, Experimentation, Human Factors, Theory,

\section{Keywords}

Culture, CSCW, survey studies, Instant Messaging, IM crosscultural communication

\section{INTRODUCTION}

In theory, information technologies (IT) could help greatly in today's era of multinational collaborations. In practice, however, cross-cultural collaborations continue to suffer from a variety of problems including a failure to understand the work context and local norms of distant team members [e.g., [2], [5]]. Cultural variance in how IT is used may account for some of these difficulties. In this paper, we explore cultural differences in the use of one type of IT-Instant Messaging (IM), or nearsynchronous text-based communication-which has been growing in popularity in the workforce. Recent studies have shown how IM can support multi-tasking, informal communication, awareness, and other team functions [e.g., [5],

Permission to make digital or hard copies of all or part of this work for personal or classroom use is granted without fee provided that copies are not made or distributed for profit or commercial advantage and that copies bear this notice and the full citation on the first page. To copy otherwise, or republish, to post on servers or to redistribute to lists, requires prior specific permission and/or a fee. CSCW'06, November 4-8, 2006, Banff, Alberta, Canada. Copyright 2006 ACM 1-59593-249-6/06/0011...\$5.00.
[7], [9]]. The vast majority of these studies, however, have been conducted in Western societies. In a world that is becoming increasingly globalized, it is important to understand whether Western patterns of IM use generalize across cultures.

Cultural theorists have distinguished several dimensions along which cultures vary that might influence IM use. The individualism-collectivism dimension reflects cultural tendencies toward acting as individuals versus acting as members of a group [[6], [12]]. Individualist, typically Western, societies emphasize individual initiative and independence. Collectivistic, typically Eastern, societies stress group solidarity and collective identity. The low-versus high-context dimension reflects the amount of contextual information required for communication [[4]]. Low context, typically Western, cultures communicate primarily through verbal information. High context, typically Eastern, cultures rely heavily on situational information (e.g., nonverbal behavior, relationship between participants) to facilitate understanding.

Several studies support the contention that media use varies across cultures. Setlock et al. [[10]] found that Chinese pairs talked more face-to-face than via IM, whereas American pairs talked equally in both media. Massey et al. [[8]] found lower satisfaction with asynchronous communication among Asian participants, which they attribute to the importance of continuous feedback in high-context cultures. Choi et al. [[1] found that Asian (high context) participants relied on visual elements in the interface to a mobile text service whereas Finnish (low context) participants did not. Other studies have examined cultural effects on IT choices, particularly within the workplace [e.g., [11]]. However, few have examined cultural patterns in the use of a single IT technology in a field setting.

In this paper, we report results of a survey of IM use in North America, India, and East Asia. Our goal is to understand how IM is used in Eastern and Western cultures so that we can design better IT solutions for cross-cultural interaction. In the remainder of this paper, we first outline the ways we expect culture to interact with IM use. We then present results from a preliminary survey and a subsequent larger survey exploring cultural differences in IM use in North America and Asia. We end by discussing the implications of the cultural differences we found.

\section{EFFECTS OF CULTURE ON IM USE}

IM use can vary in many ways, including selection of an IM client, use of client-specific features, and individual communication styles. Popular IM clients (e.g., AIM, MSN, Yahoo) share basic features: they are text-based, they provide 
buddy lists in which contacts can be stored, and they allow for near-synchronous message exchange. At the same time, IM clients differ in certain ways. Features such as audio or video chat, and offline messages are not universal. People also vary in their styles of IM use - for example, whether they keep windows open all day and whether they hold parallel conversations. In this section, we explore how the cultural dimensions of individualismcollectivism and high-low context affect IM use.

Synchronicity of communication: IM can be used synchronously, semi-synchronously or asynchronously. Because high-context cultures use more contextual/ nonverbal communication cues, members need to convey understanding and ensure that they have been understood. We thus hypothesize that Asians will prefer to use IM synchronously. In contrast, North Americans (low context) will be more likely to use IM semi-synchronously or asynchronously because they do not feel pressed to give or receive immediate feedback.

Single vs. multiple Windows: People can talk to one buddy at a time or several buddies in parallel. Having multiple active conversations, however, can result in delayed responses to messages. We hypothesize that members of high-context cultures will want to attend more fully to each conversation, keeping synchronicity high. They will therefore have fewer open windows at the same time. Members of low-context cultures will not expect immediate feedback. They will be more likely to open multiple windows and hold intermittent conversations [c.f., [9]].

Single vs. multi-party chat: Many IM tools support multi-party chats, in which users can talk with more than one buddy in the same IM window, similar to a teleconference. We anticipate that members of collectivistic cultures will make greater use this feature than individualistic ones because they prefer making decisions in group settings rather than individually [[3]].

Audio-video chat. While numerous IM clients are moving toward supporting audio/video interaction, the preponderance of previous work has failed to show a benefit of video [c.f. [14]]. Most of these studies, however, have been performed in Western, lowcontext cultures. Because video has been shown to be useful when facial expressions and lip movements help disambiguate speech [[13]], we anticipate that the value of video will be higher for high-context cultures.

Emoticons. Most IM clients provide a variety of emoticons that can be used during conversations. We expect that in high-context cultures, use of emoticons will be more frequent in order to supplement the low-context media. This will be less necessary in low-context cultures

\section{PRELIMINARY STUDY}

We conducted a preliminary survey in which 34 IM users (19 North Americans and 15 Asians from India and Thailand) responded to questions about IM behaviors, including IM client choices, clients, number of open windows, and use of emoticons. Several differences were found between the North American and Asian participants:

Choice of IM client. We found large cultural differences in preferred IM client. Among North Americans, AIM was by far the preferred client, with $100 \%$ of respondents reporting using it on a regular basis. Much fewer used MSN (33\%) or Yahoo
(18\%). In Asia, MSN (82\%) and Yahoo (82\%) were preferred, and only $13 \%$ used AIM.

Single vs. multi-party chat. A higher percentage of Asians (73\%) than of North Americans (5\%) used multi-party chat. This finding is consistent with a collectivistic approach to discussion and decision-making.

Single vs. multiple windows. A greater percentage of Americans $(61 \%)$ than of Asians (13\%) reported conducting multiple IM conversations in parallel. This finding is consistent with a need to be fully focused on one's conversational partner in high-context cultures.

Emoticons. A greater percentage of Asians (100\%) than North Americans (72\%) reported using emoticons on a regular basis. These findings are partially consistent with the hypothesis that emoticons will be more important in Eastern, high-context cultures.

The results suggest interesting differences in IM use across cultures. However, the sample size was small, and the confounding of culture and IM client makes it unclear whether differences in behavior were driven by client features or by culture (e.g., it could be easier to establish a multi-party conversation in MSN). To address these issues, we conducted a larger, better-controlled study.

\section{MAIN SURVEY}

Participants from North America, a low-context culture, and, India and East Asia, both high-context cultures, responded to an online survey about their IM use. The sampling of North Americans was done such that approximately half of the respondents were MSN users.

\subsection{Participants}

Seventy-eight participants between the ages of 20 and 30, all fluent in English, completed the survey. Of these, 28 were North American, 21 were Indian and 29 were from East Asia (26 from Singapore, 2 from China and 1 from Hong Kong). Slightly over half were male. All were graduate students or young professionals, recruited through electronic mailing lists and bulletin boards (like Yahoo Groups) from the management and engineering fields. Asian participants had grown up in either India or East Asia, although several had spent a short time (typically less than a year) in the United States. They received \$30 Amazon gift certificates for their participation.

\subsection{Materials}

An English-language survey addressed four sets of questions:

Basic IM Use. Participants indicated their overall use of IM, including how long they had been using IM, location of IM use (home vs. work), number of IM windows opened/closed per day, number of buddies on their lists, and typical length of an IM session.

Choice of IM client. Participants reported their use of five IM clients-AIM, MSN, Yahoo, ICQ and iChat - on a 5-point scale ranging from never to every day. Spaces were provided for entering names of additional IM clients. 
Use and perceived value of specific IM features. Participants indicated how often they used multi-party chat and offline messages (sent to a buddy who is not currently logged on) on a scale of 1 (never) to 5 (more than once a week). They also indicated whether they kept IM windows open when not actively chatting. Finally, they rated the importance of features such as video chat and emoticons on a scale of 1 (not at all important) to 5 (very important).

Demographic and socio-cultural measures. Participants indicated their age, gender, occupation, country of birth, country of residence, native languages, languages used for IM, and ethnic identity. Demographic and cultural questions appeared at the end of the survey, so as not to focus the respondents' attention on cultural issues.

\section{RESULTS}

Differences between cultural groups were assessed by Analysis of Variance (ANOVA) and Chi-Square tests where appropriate. Post-hoc tests were used to compare specific cultures when an overall ANOVA was significant.

\subsection{Basic IM Use}

Cultural groups were fairly well equated in terms of basic IM use. Chi-square tests indicated no significant differences between cultural groups in terms of how long they had been using IM or in terms of whether they used it mostly for work, mostly for personal, or for both work and personal communication. The vast majority of respondents in all groups had used IM for 3 years or longer (89.3\% of North Americans, $90.5 \%$ of Indians, and $86.2 \%$ of East Asians). Approximately two-thirds of respondents in each category used IM predominantly for personal communication and another third used it for both personal and work-related communication. Only one respondent (a North American) reported using IM solely for work purposes.

All respondents reported opening a mean of 5 to 10 windows a day $(\mathrm{F}[2,75]<1$, ns) and sending 10 to 50 messages a day ( $\mathrm{F}[2$, $75]<1$, ns). Cultural groups also did not differ in the mean number of buddies on their lists $(\mathrm{F}[2,75]=1.46, n s)$.

\subsection{Use of Specific IM Clients}

Table 1 shows IM client use as a function of cultural group. Among North Americans, the most popular client was AIM, followed by MSN (but note that half of the North Americans were recruited on the basis of MSN use). Among Indians, Yahoo was most popular, followed by MSN. Among East Asians, MSN was most popular followed by AIM. These results replicate our earlier findings of cultural differences in preferred IM clients.

Table 1. Percentage of participants reporting daily use of IM clients by cultural group.

\begin{tabular}{|l|c|c|c|}
\hline & $\begin{array}{c}\text { North } \\
\text { American }\end{array}$ & Indian & $\begin{array}{c}\text { East } \\
\text { Asian }\end{array}$ \\
\hline ICQ & $4 \%$ & $0 \%$ & $38 \%$ \\
AIM & $65 \%$ & $6 \%$ & $59 \%$ \\
MSN & $46 \%$ & $63 \%$ & $76 \%$ \\
Yahoo & $20 \%$ & $86 \%$ & $22 \%$ \\
iChat & $13 \%$ & $7 \%$ & $0 \%$ \\
\hline
\end{tabular}

\subsection{Use and perceived value of Specific IM Features}

Synchronicity of communication. The data on basic IM use suggests no differences between culture groups in terms of how synchronously they used the medium. However, the groups did differ in how frequently they sent offline messages to their buddies $(F[2,75]=8.19, \mathrm{p}<.001)$, and post-hoc tests indicated that all three groups differed significantly from one another. Mean frequencies on a scale of 1 (never) to 5 (more than once a week) were 2.14 for North Americans, 3.81 for Indians, and 2.97 for East Asians. This finding may stem from differences in IT infrastructure (i.e., availability of internet access) and preferred IM clients (this feature is available on Yahoo).

Single vs. multiple windows. Participants indicated how many IM windows they had open at the same time on a scale ranging from 1 (one window) to 3 (more than two windows). Contrary to expectations, there were no differences between groups in terms of the number of parallel sessions $(\mathrm{F}[2,75]<1, n s)$. More than $80 \%$ of all groups had at least two windows open at the same time

Single vs. multi-party chat. North Americans reported significantly less use of multi-party chat than did Indians or East Asians. Means for North Americans, Indians, and East Asians were $2.29,2.90$ and 3.17, respectively, on a scale of 1 (never) to 5 (more than once a week) $(\mathrm{F}[2,75]=4.87, \mathrm{p}=.01)$. Choice of IM client had no affect on North Americans' use of chat. Only two of 13 North Americans who were frequent MSN users reported using multi-party chat once a week or more, versus one of 17 daily AIM users. Thus, cultural differences in multi-party chat are unlikely to be due to differences in IM clients.

Audio-Video chat. Participants rated the importance of audio and video chat on a scale of 1 (not at all important) to 5 (very important). As shown in Table 2, groups differed in their importance ratings for both IM features (for audio, $\mathrm{F}[2,75]=$ $7.65, \mathrm{p}<.001$; for video, $\mathrm{F}[2,75]=3.21, \mathrm{p}<.05)$. In both cases, North Americans rated the feature lowest and Indians rated it highest in importance.

Emoticons. As expected, there were cultural differences in rated importance $(\mathrm{F}[2,75]=3.24, \mathrm{p}<.05)$. Post-hoc tests indicated that North Americans rated emoticons significantly lower in importance than did Indians, and marginally $(p=.09)$ lower in importance than East Asians.

Table 2. Mean rated importance of IM feature by cultural group $(1=$ not at all important; $5=$ very important $)$.

\begin{tabular}{|l|c|c|c|}
\hline & $\begin{array}{c}\text { North } \\
\text { American }\end{array}$ & Indian & $\begin{array}{c}\text { East } \\
\text { Asian }\end{array}$ \\
\hline Audio Chat & 1.89 & 3.05 & 2.38 \\
Video Chat & 2.00 & 2.81 & 2.38 \\
Emoticons & 2.61 & 3.29 & 3.03 \\
\hline
\end{tabular}

\section{DISCUSSION}

Overall, the results indicate significant differences in how North Americans and Asians use IM. Multi-party chat, emoticons and audio-video chatting were much more popular in Asia than in North America. These results are consistent with cultural differences in individualism-collectivism and low- vs. highcontext communication, 
Although a cultural explanation is appealing, there are several alternatives that must be considered. First, IM behaviors may be based on group norms that have arisen independently from deeper cultural differences. Second, language differences may play a role. Languages such as Hindi and Chinese that use non-Western characters can be awkward for text-based communication, making audio and video more desirable. Finally, differences in IT infrastructure, such as the availability of continuous Internet access and cell phone service, may affect the popularity of features such as offline messages.

Although we cannot determine specific causes from the current study, our results make it clear that Eastern and Western cultures differ in IM use in ways that should be taken into consideration when designing tools for cross-cultural communication. For example, the results suggest that cultures place different degrees of importance on optional IM features such as video or audio conferencing. Future IM clients should be designed to help people from one culture understand that those from other cultures may have different preferences. For example, users could be asked to specify their preferences for optional features such as video and these preferences could be conveyed to anyone starting an IM conversation with them. Alternatively, a system might learn users' preferences by observing their IM behavior and display these preferences to new IM partners. By helping people learn about one another's cultural preferences for communication, new tools may be able to facilitate cross-cultural collaboration.

\section{ACKNOWLEDGEMENTS}

This material is based upon work supported by the National Science Foundation under Grants \#0325087 and \#0329077. We thank Daniel Avrahami for questionnaire assistance, Lui Min Oh for help recruiting Singaporean respondents, Adam McCue for implementing our web survey, and Gail Kusbit for editorial assistance.

\section{REFERENCES}

[1] Choi, B., Lee, I., Kim, J., and Jeon, Y. (2005) A qualitative cross-national study of cultural influences on mobile data service design. Proc. CHI 2005. ACM Press.

[2] Cramton, C. D. (2001). The mutual knowledge problem and its consequences for dispersed collaboration. Organizational Science, 12, 346-371
[3] Gudykunst, W., and Ting-Toomey, S. (1988). Culture and interpersonal communication. Newbury Park, CA: Sage.

[4] Hall, E. (1976/1981). Beyond culture. NY: Doubleday.

[5] Herbsleb, J. D., Mockus, A., Finholt, T. A., and Grinter, R. E. (2000). Distance, dependencies, and delay in a global collaboration. Proc. CSCW 2000 (pp. 319-328). ACM Press.

[6] Hofstede, G. (1983). Dimensions of national cultures in fifty countries and three regions. In J. Deregowski, S. Dzuirawiec \& R. Annis (Eds.), Explications in Cross-Cultural Psychology.

[7] Isaacs, E., Walendowski, A., Whittaker, S., Schiano, D. J., and Kamm, C. (2002). The character, functions, and styles of instant messaging in the workplace. Proc. CSCW 2002, 1120. ACM Press.

[8] Massey, A., Montoya-Weiss, M., Hung, C., and Ramesh, V. (2001) When culture and style aren't about clothes: Perceptions of task-technology "fit" in global virtual teams. Proc. Group 2001 (pp. 207-213). ACM Press.

[9] Nardi, B.A., Whittaker, S., and Bradner, E. (2000) Interaction and outeraction: Instant messaging in action. Proc. CSCW 2000 (pp.79-88). ACM Press.

[10] Setlock, L. D., Fussell, S. R., and Neuwirth, C. (2004). Taking it out of context: Collaborating within and across cultures in face-to-face settings and via instant messaging. Proc. CSCW 2004 (pp. 604-613). ACM.

[11] Teng, J., Calhoun, K. Cheon, M. Raeburn, S., and Wong, W. (1999) Is the East really different from the West: A crosscultural study on information technology and decision making. Proc. 20th International Conference on Information Systems (pp. 40-46). Atlanta: AIS .

[12] Triandis, H. C. (1989). The self and behavior in different cultural contexts. Psychological Review, 96, 506-520.

[13] Veinott, E., Olson, J., Olson, G., and Fu, X. (1999) Video helps remote work: Speakers who need to negotiate common ground benefit from seeing each other. Proc. CHI 1999 (pp. 302-309). ACM Press.

[14] Whittaker, S. (2003). Theories and methods in mediated communication. In Graesser, A., Gernsbacher, M., and Goldman, S. (Ed.) The Handbook of Discourse Processes (pp. 243-286). Mahwah, NJ: Erlbaum. 